\title{
ALLOY 706 METALLURGY AND TURBINE WHEEL APPLICATION
}

\author{
P.W. Schilke, J.J. Pepe, R.C. Schwant \\ Materials and Processes Engineering \\ GE Power Generation \\ Schenectady, NY
}

\begin{abstract}
The basic chemistry of Alloy 706 was developed from Alloy 718 more than 20 years ago but until recently has not been applied to gas turbines. Its excellent chemistry balance has allowed very large ingots to be produced and successfully forged into high quality turbine wheel forgings. This paper describes the metallurgy of Alloy 706, improvements recently made to enhance its producibility and improve its properties, and its application to turbine wheels. A brief review of ultrasonic inspectability is also presented.
\end{abstract}

\section{Introduction}

Alloy 706 has lived in the shadow of its predecessor, Alloy 718, since it was developed more than 20 years ago. Recently, Alloy 706 has begun to be used in heavy duty industrial gas turbine wheel applications, (see Figure 1). New developments have resulted in the production of Alloy 706 ingots weighing more than 33,000 pounds and forgings weighing more than 22,000 pounds, with thicknesses of more than 16 inches and diameters of up to 87 inches. This paper briefly describes the history of the alloy, its current application to high temperature gas turbines, and the recent work done at General Electric Power Generation to optimize alloy processing and scale-up the size of the forgings made from this alloy. This paper also describes new non-destructive inspection techniques used to inspect these turbine forgings to greater levels of sensitivity than previously possible.

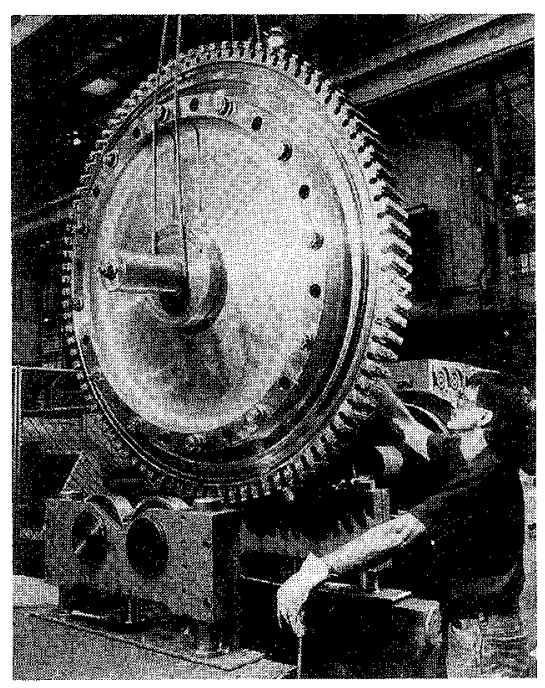

Figure 1. Heavy Duty Industrial Gas Turbine Wheel 


\section{Alloy 706 Derivation and Metallurgy}

Alloy 706, a nickel-iron superalloy, evolved from studies performed at the International Nickel Company (INCO) in the 1950's. These studies involved investigation of the strengthening effects of various common alloy elements $(\mathrm{Cr}, \mathrm{Mo}, \mathrm{Nb}, \mathrm{Al}$ and $\mathrm{Ti})$ in an Alloy 600 alloy base metal(1). The alloy was originally developed as a higher strength main steam piping material for super critical steam power plants which were being planned by U.S. utilities at that time. During the development process, the potent combined strengthening effects of molybdenum and niobium alloyed with varying amounts of nickel were discovered. This led to the eventual development of Alloy 718, then Alloy 625 and finally Alloy 706, which was patented in 1972. The nominal chemistries of these alloys are shown in Table 1.

Table 1 Chemistries of Several Related Alloys

\begin{tabular}{|l|c|c|c|c|c|c|c|c|r|r|}
\hline Alloy & $\mathrm{C}$ & $\mathrm{Mn}$ & $\mathrm{Si}$ & $\mathrm{Cr}$ & $\mathrm{Ni}$ & $\mathrm{Fe}$ & $\mathrm{Ti}$ & $\mathrm{Al}$ & $\mathrm{Mo}$ & $\mathrm{Nb}+\mathrm{Ta}$ \\
\hline 600 & 0.08 & 0.50 & 0.20 & 15.5 & 76.0 & 8.0 & - & - & - & - \\
\hline 718 & 0.04 & 0.20 & 0.20 & 19.0 & 52.5 & 18.5 & 0.9 & 0.5 & 3.0 & 5.1 \\
\hline 625 & 0.05 & 0.20 & 0.20 & 21.5 & 61.0 & 2.5 & 0.2 & 0.2 & 9.0 & 3.6 \\
\hline 706 & 0.03 & 0.20 & 0.20 & 16.0 & 41.5 & 40.0 & 1.8 & 0.2 & - & 2.9 \\
\hline
\end{tabular}

The Alloy 706 development program at INCO had some very specific metallurgical objectives ${ }^{(2)}$. Among these were (1) an alloy which could be melted freckle free to larger sizes than Alloy 718, (2) an alloy which could be hot worked within the capabilities of existing forging capacity in these large ingot sizes, (3) an alloy which was more economical than Alloy 718 and finally, (4) an alloy which had better machinability than Alloy 718 .

The Alloy 706 chemistry was derived from Alloy 718 and was developed from a large statistically designed melting program by H.L. Eiselstein. Molybdenum, which is present in Alloy 718 as a solid solution strengthener, was eliminated in Alloy 706 to improve forgability. Niobium was reduced to decrease the tendency for segregation and freckle formation. But since the primary hardening elements are $\mathrm{Nb}$ and $\mathrm{Ti}$, the percentage of titanium was increased to compensate for the lowered niobium content. A low level of aluminum was chosen to provide some strengthening while avoiding rapid age hardening, which would make welding difficult. The chromium content was selected to achieve good oxidation resistance and low magnetic permeability; the nickel level was chosen to be as low as possible to decrease cost, yet maintain phase stability and avoid formation of sigma phase. Finally, carbon was decreased to ensure good machinability.

The most important precipitating phases that occur in Alloy 706 and their typical morphologies are shown in Table 2.

Table 2 Major Precipitates in Alloy 706

\begin{tabular}{|l|l|l|l|}
\hline Precipitate & \multicolumn{1}{|c|}{ Structure } & Morphology & Composition \\
\hline Gamma Prime $\left(\gamma^{\prime}\right)$ & Ordered Face Centered Cubic & Spheres & $\mathrm{Ni}_{3}(\mathrm{Al}, \mathrm{Ti})$ \\
\hline Gamma Double Prime $\left(\gamma^{\prime \prime}\right)$ & $\begin{array}{l}\text { Ordered Body Centered } \\
\text { Tetragonal }\end{array}$ & Disks & $\mathrm{Ni}_{3} \mathrm{Nb}$ \\
\hline Laves & Hexagonal Close Packed & Globular & $(\mathrm{Fe}, \mathrm{Ni})_{2} \mathrm{Nb}$ \\
\hline Eta $(\eta)$ & Hexagonal Close Packed & $\begin{array}{l}\text { Platelets or } \\
\text { Cellular }\end{array}$ & $\mathrm{Ni}_{3} \mathrm{Ti}$ \\
\hline Delta $(\delta)$ & Orthorhombic & Needles & $\mathrm{Ni}_{3} \mathrm{Nb}$ \\
\hline
\end{tabular}


Both gamma prime $\left(\gamma^{\prime}\right)$ and gamma double prime $\left(\gamma^{\prime \prime}\right)$ are present in Alloy 706 as strengthening precipitates with $\gamma^{\prime \prime}$ the more prevalent phase ${ }^{(3)}$. In addition to these phases, other precipitates seen in this alloy are MC carbides, Laves and eta $(\eta)$. Other investigators have reported the presence of delta phase $(\delta)$ but we have not observed this phase in our work. Eiselstein's $\mathrm{s}^{(4)}$ original time-temperaturetransformation diagram is shown in Figure 2. This diagram does not show the $\gamma^{\prime \prime}$ transformation. An updated version by Heck ${ }^{(5)}$, which shows the $\gamma^{\prime \prime}$ transformation, will be presented as part of this conference. Both $\gamma^{\prime}$ and $\gamma^{\prime \prime}$ can be put back into solution by holding at $1625^{\circ} \mathrm{F}\left(885^{\circ} \mathrm{C}\right)$. Eta and Delta are resolutioned at about $1750^{\circ} \mathrm{F}\left(954^{\circ} \mathrm{C}\right)$, ${ }^{(6)}$ but as we will show later, segregated areas with slightly higher levels of $\mathrm{Nb}$ and $\mathrm{Ti}$ may require slightly higher

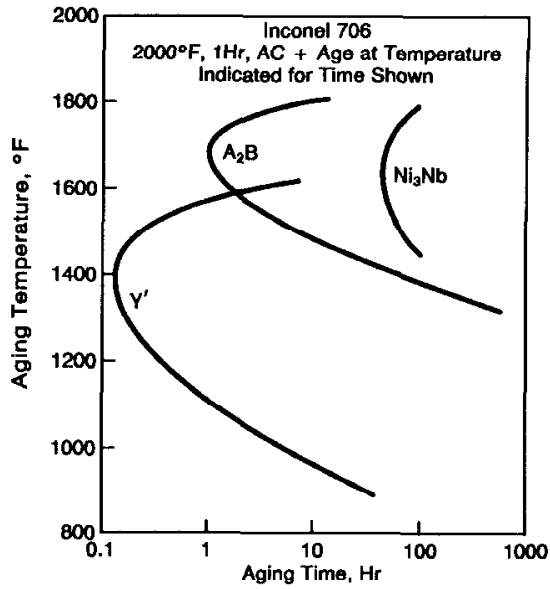

Figure 2. Time-TemperatureTransformation Diagram According to Eiselstein temperatures. Small grain boundary particles of Laves can be resolutioned at $1950^{\circ} \mathrm{F}$ $\left(1066^{\circ} \mathrm{C}\right)$ but large Laves particles which may result from poor melt practices can survive temperatures in excess of $2000^{\circ} \mathrm{F}\left(1093^{\circ} \mathrm{C}\right)$. An excellent discussion of the effect of heat treatment and resulting precipitating phases can be found in an article by Moll, et al. ${ }^{(7)}$.

\section{Gas Turbine Application}

The turbine rotor design of all General Electric heavy-duty land-based gas turbines is a bolted construction of forged turbine wheels, spacers, and stub shafts. The most highly stressed components in the turbine rotor are the turbine wheels. Historically, CrMoV low alloy steel wheels have been used extensively in heavy-duty gas turbine designs because the high stresses at relatively low temperatures could be accommodated by this low-cost, easily fabricated material.

In the mid 80's, a new class of "advanced" gas turbines, now known as the " $\mathrm{F}$ " class turbines, firing at $2300^{\circ} \mathrm{F}\left(1260^{\circ} \mathrm{C}\right)$, was introduced by GE. These machines, operating at temperatures more than $300^{\circ} \mathrm{F}\left(166^{\circ} \mathrm{C}\right)$ higher than the previous generation of industrial gas turbines, required a wheel material with higher yield strength at elevated temperature.

Alloy 706 was selected for this application because of its good mechanical properties, ease of fabrication, and good machinability. A review of commercial alloys showed that only Alloy 706 and Alloy 718 possessed the required strength at temperature for the " $\mathrm{F}$ " class machines. The ability to produce large ingot diameters was also a necessity. Ingot diameters exceeding 30 inches were required to avoid exceeding the ingot's length-to-diameter ratio where buckling of the ingot may occur during upsetting. The maximum reported Alloy 718 ingot diameter that had been made without freckling was approximately 24 inches in diameter. Above this size freckling could not be prevented. However, previous good experience (summarized below) had been documented with Alloy 706 in sizes up to almost 12,000 pounds ${ }^{(8)}$, and Suarez, et al. ${ }^{(9)}$ reported that 30 inch electro slag remelted (ESR) ingots might be attainable. In addition, Alloy 706 was reported to have substantially better machinability than Alloy $718^{(10)}$. 


\section{Early Alloy 706 Experience}

A development program was conducted in the mid 70's by GE to assess the feasibility of making large industrial gas turbine Alloy 706 wheels and to determine the resultant properties ${ }^{(8)}$. The ingot, produced by the ESR process, measured approximately 24 inches in diameter by approximately 90 inches long and weighed 11,700 pounds. The forge practice consisted of an initial upset, a draw, a second upset and a final forge operation. The final forge operation was carried out at $2,000^{\circ} \mathrm{F}\left(1093^{\circ} \mathrm{C}\right)$ and the earlier steps at slightly higher temperature.

The wheel was machined and sectioned. Portions of the wheel were given either a two or a three step aging heat treatment. The wheel sections were ultrasonically tested using a 2.25 $\mathrm{MHz}$ crystal calibrated on a 5/16 in. flat bottom hole. Up to 5 inches of thickness could be penetrated with this technique and no indications were found. In order to penetrate the thicker sections, a $1 \mathrm{MHz}$ crystal was used, and no indications were found at this frequency.

This program showed that a large Alloy 706 ingot could be successfully made, forged into a large wheel shape and heat treated to achieve good property levels. It also demonstrated that this material had significantly less sonic penetrability than low alloy steel.

\section{Current Alloy 706 Experience}

\section{Chemistry}

The chemistry of Alloy 706 today is much the same as it was when it was introduced in the early 1970's. Standard specifications for Alloy 706 have wide limits for the various chemical elements. Melters of Alloy 706 generally control each element of the chemistry within their own narrower range; but nonetheless, the chemistry variation between melters can lead to variations in the results obtained by forgers. The characteristics which may be affected are toughness, ductility, grain size, and yield strength. Several changes have been made to the chemistry specification for turbine wheels to improve the producibility of these large forgings.

Silicon. To reduce the tendency for formation of Laves phase, the maximum allowable silicon level has been decreased to below 0.10\%. Standard heats of Alloy 706 are made with silicon contents of 0.10 to $0.30 \%$. At the high end of this range, Laves begins to precipitate at grain boundaries within one hour at a temperature of $1700^{\circ} \mathrm{F}$. Large disc forgings which are air cooled through this temperature range can precipitate extensive grain boundary networks of Laves even at the lower end of this silicon range, and Charpy impact values can dip to as low as $5 \mathrm{ft}-1 \mathrm{bs}$. Water quenching eliminates most of the Laves but interdendritic segregation can still lead to some Laves formation. Below $0.10 \% \mathrm{Si}$, Laves phase precipitation is minimized so that even air cooling of large forgings is possible.

Niobium/Tantalum/Titanium. Changes in the levels of $\mathrm{Nb}$ and $\mathrm{Ti}$ affect the solvus temperature for eta phase. Eta phase at grain boundaries can reduce tensile ductility and CVN (Charpy V notch) toughness but not to the same extent as Laves. Eta at grain boundaries can also affect the grain size, as discussed below. Increasing levels of $\mathrm{Nb}$ and Ta promote the tendency for the alloy to form freckle defects during solidification. By optimizing levels of $\mathrm{Nb}$ and $\mathrm{Ti}$ within a narrow range, a good balance of strength and toughness can be achieved while reducing scatter in mechanical properties.

Carbon. Toughness, which is a critical property for turbine wheels, is affected by carbon content. Laboratory studies of heats with varying levels of hardening elements showed 


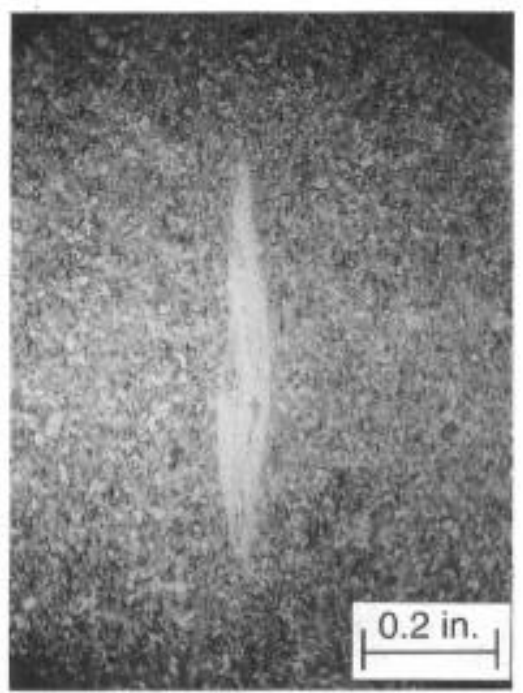

Figure 3. Dirty White Spot in Alloy 706

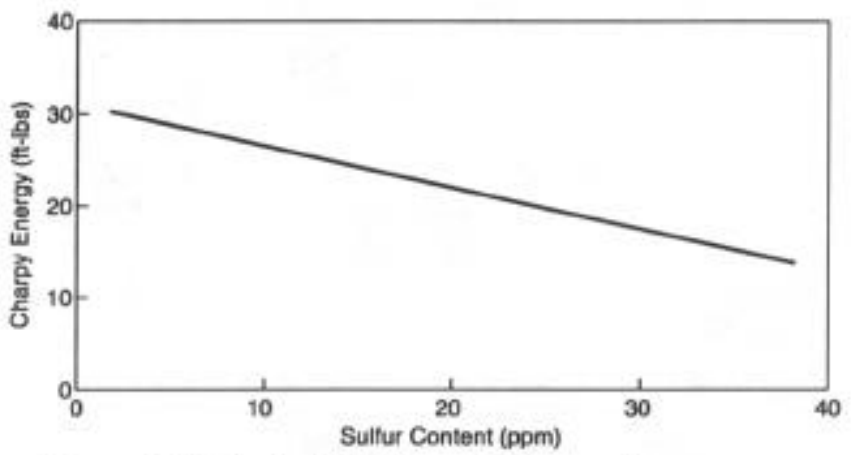

Figure 4. Effect of Sulfur on Charpy Energy

improvement of approximately $20 \mathrm{ft}-\mathrm{lbs}$ in Charpy tests when the carbon level was reduced from a nominal level of $0.03 \%$ to a nominal level of $0.01 \%$. Reduced carbon can also be expected to improve machinability through reduction of the number of carbides formed.

Oxygen and Nitrogen. Oxygen and nitrogen levels are not always called out in commercial specifications. There is, however, a benefit in controlling these elements that comes from avoidance of potential problems with "dirty white spots." White spots are areas of negative segregation, that is, areas of lower $\mathrm{Nb}$ and $\mathrm{Ti}$ content. Nitrides and oxides found in dirty white spots (see Figure 3 ) are likely initiation sites for early low cycle fatigue failures. Minimizing the oxygen and nitrogen limits the number and size of oxide and nitride inclusion clusters that may occur. To achieve this beneficial effect, the level of oxygen and nitrogen must each be held substantially below $50 \mathrm{ppm}$.

Sulfur. Low axial Charpy energy, tensile strength, and tensile ductility were observed in some early trial forgings. The cause was $(\mathrm{Ti}, \mathrm{Nb})_{2} \mathrm{CS}$, a deformable phase that can cause reduced properties in the short transverse direction of heavily forged parts. This phase smears out into planes of weakness perpendicular to the forging direction. Tests performed on two laboratory heats which were rolled into small bars and heat treated together showed significant improvements in longitudinal CVN (see Figure 4) as a result of lowering the sulfur level. Reducing sulfur to below commercial specification levels has led to an improvement in axial Charpy values of production parts and has truncated the lower end of the Charpy value distribution.

\section{Melting}

The development of large, high-quality Alloy 706 ingots mandated significant enhancements to the historical melting technology used for this alloy to prevent the formation of melt-related defects. A triple melt process consisting of vacuum induction melting (VIM), electroslag remelting (ESR), and vacuum arc remelting (VAR) was adopted based upon previous work done on Alloy 718 for aircraft industry applications. The VIM process provides a clean starting material with a well-controlled chemistry. ESR provides some refining of the metal and a sound electrode which remelts in the VAR furnace with little potential for melting anomalies. VAR was chosen as the final melting operation because the shallow melt pools created by this process make it the least likely to cause segregation-related defects. 
Freckle segregation can occur in Alloy 706, as it does in Alloy 718 but, because there is less $\mathrm{Nb}$ and Ta than in Alloy 718, there is less tendency to form freckles. Freckles are regions of high $\mathrm{Nb}$ and Ta content. They typically contain some low-ductility Laves phase which can decrease fatigue properties. In addition, the freckles may develop micro cracks after forging, as shown in Figure 5. Since Alloy 706 is less prone to freckle formation than Alloy 718, it has been possible to produce larger VAR ingots. VAR molds as large as 40 inches in diameter have been successfully cast. Melt rate controls and drip-short controls are used in conjunction with low melt rates to control the tendency for freckling. Melt rate excursion limits have been established through cut-up of many trial ingots to verify that the melt conditions are sufficiently controlled, and macroetching is done to ensure freckle free ingots.

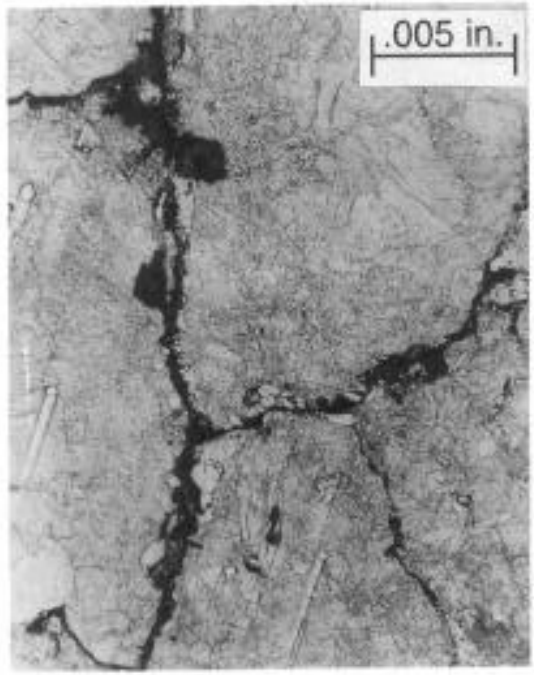

Figure 5. Cracks in Freckle Region of Alloy 706.

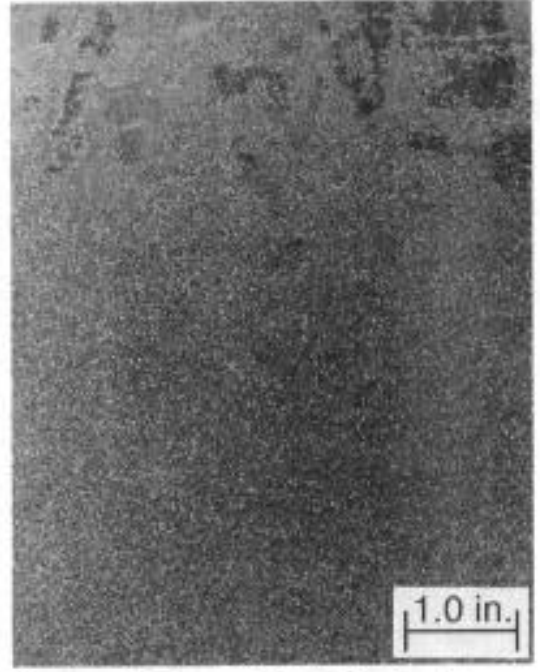

Figure 6. Large Cast Grain Structure (top) in Alloy 706.

White spots, or areas of low alloy ( $\mathrm{Nb}$ and $\mathrm{Ti}$ ) content, can occur in Alloy 706. The types of white spots found in Alloy 706 are the same as the types found in Alloy 718, as described by Jackman et al. (11). "Discrete" white spots have been found in material melted by the VIM/VAR process but have not been found in triple melted material. "Non-discrete" or "solidification" white spots can occur in the normally cropped regions at the bottom and top end of the ingot. However, testing has shown that these white spots have little or no impact on the mechanical properties. Further discussion of our evaluations of white spots and freckles can be found in reference ${ }^{(12)}$.

\section{Forging}

Forging of turbine disks is accomplished in several steps. Multiple upset and draw operations of the ingot are performed to break up the initial large as-cast grain size. Special handling and lubrication is used to avoid die lock and assure working of all areas of the forging. This is important because remnants of large as-cast structure (see Figure 6) may not get refined during the final forge operations. Tests have shown that fatigue crack growth rates in large grains can be up to three times higher relative to the surrounding fine grained matrix.

The minimum forge work required for recrystallization in Alloy 706 billet is only about $15 \%$, but in practice significantly more work is applied during each operation to ensure that full recrystallization is attained in all areas of a component. In press forging operations, most of the recrystallization occurs after the forging operation (static recrystallization). Complete dynamic recrystallization (during forging) cannot be 
achieved at the strain rates used for a forge press at strains up to 0.7 inch per inch even at temperatures as high as $2000^{\circ} \mathrm{F}\left(1093^{\circ} \mathrm{C}\right)$. Static recrystallization does not occur below $1700^{\circ} \mathrm{F}\left(927^{\circ} \mathrm{C}\right)$, but full recrystallization can be achieved as low as $1750^{\circ} \mathrm{F}\left(954^{\circ} \mathrm{C}\right)$.

Final forging of the biggest Alloy 706 land based turbine wheels can only be accomplished on the largest forge presses available in the world, rated at 72,000 tons $(65,000$ tons metric). It is necessary to use a large press in order to minimize the forge temperature while achieving uniform working of the full part. The temperature used during actual forging has very little effect on the grain size obtained after heat treatment. However, higher forge temperatures lead to larger grain size due to grain growth, which occurs during cooling after the forging operation. Large grain size severely hampers ultrasonic inspection of the forging and reduces fatigue life. Therefore, avoidance of high temperatures both during heat treatment and while the part cools from the forge press is important to achieve optimum microstructure and mechanical properties.

Grain size control of Alloy 718 is often achieved by forging the material after small particles of delta phase have been precipitated on the grain boundaries. The particles pin the grain boundaries and prevent grain growth. An analogous process can be employed for Alloy 706 using eta phase ${ }^{(6,13,14)}$. However, the flow stress of Alloy 706 increases dramatically, thus increasing forge press requirements. Figure 7 shows a comparison of the flow stress of Alloy 706 at $1600^{\circ} \mathrm{F}\left(871^{\circ} \mathrm{C}\right)$, which is below the eta solvus and at $2000^{\circ} \mathrm{F}$, $\left(1093^{\circ} \mathrm{C}\right)$, which is well above the solvus.

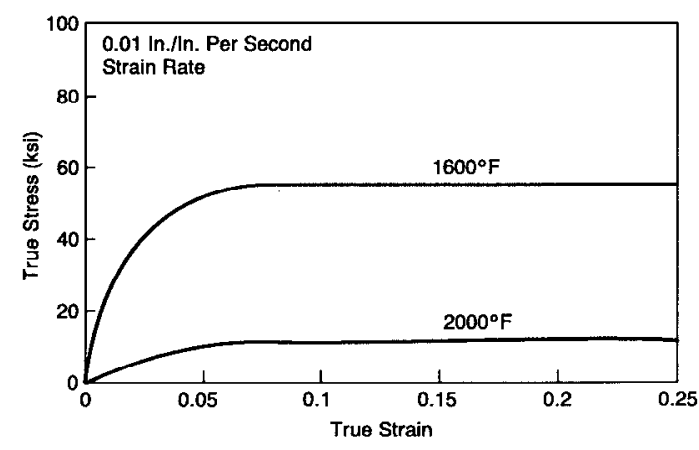

Figure 7. IN-706 Flow Stress

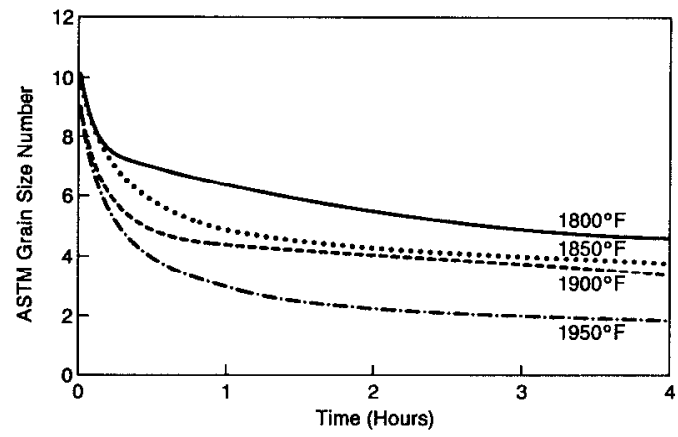

Figure 8. Grain Growth of IN-706

\section{$\underline{\text { Heat Treatment }}$}

Alloy 706 is typically used in a solution treated and aged condition. The strengthening phases, gamma prime and gamma double prime, are completely dissolved above about $1625^{\circ} \mathrm{F}\left(885^{\circ} \mathrm{C}\right)$. However, the solution temperature is usually chosen to be in the range of $1800^{\circ} \mathrm{F}\left(982^{\circ} \mathrm{C}\right)$ to $1850^{\circ} \mathrm{F}\left(1010^{\circ} \mathrm{C}\right)$ to avoid eta and Laves phase precipitation. Higher solution temperatures are generally avoided because grain growth is very rapid and large grains may harm fatigue properties and hinder ultrasonic inspection. Figure 8 shows the time for material with an initial grain size of ASTM 10 to reach various grain sizes at different temperatures.

Turbine wheels are given a combination recrystallization/solution treatment following forging. The optimum treatment temperature is around $1800^{\circ} \mathrm{F}\left(982^{\circ} \mathrm{C}\right)$. At this temperature all of the grains recrystallize, but excessive grain growth is avoided. Below $1750^{\circ} \mathrm{F}$ $\left(954^{\circ} \mathrm{C}\right)$, recrystallization may not be complete and eta phase may exist at grain boundaries or within grains. Eta is effective in controlling grain size by pinning the boundaries. If material with eta in the grain boundaries is heated to a temperature around the eta solvus, bands of large and small grains may form. This is caused by residual interdendritic 
segregation, causing variations in the local eta solvus. The temperature range over which the banding appears is dependent on the nominal $\mathrm{Nb}$ and Ti contents, as shown in Figure 9.

Water or oil quenching after solution treatment can prevent precipitation of eta or Laves phase in the deep-seated regions of large forgings. Quenching also limits the time at solution temperature, thereby minimizing grain growth. Cracking is avoided as long as the surface is free from defects and large stress concentrations.

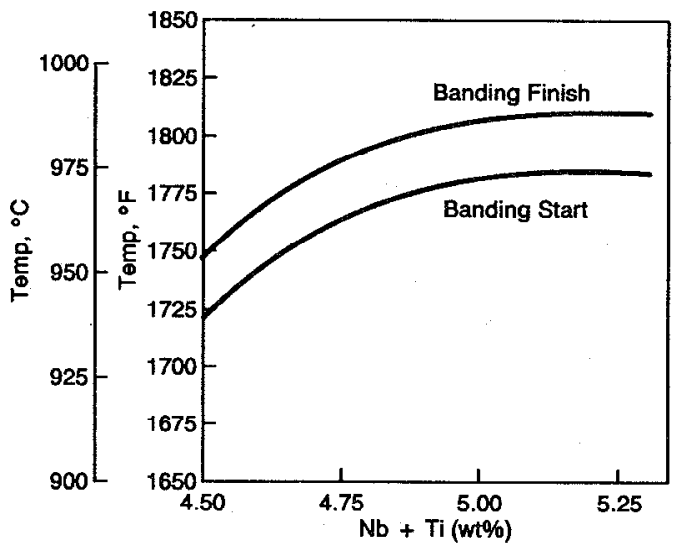

One of two aging treatments originally developed by INCO is generally applied to Alloy 706 when it is aged today. A three-step aging

Figure 9. Effect of $\mathrm{Nb}+\mathrm{Ti}$ on Banding in Alloy 706. process is used for applications where high temperature stress rupture ductility is required, and a two-step aging process is employed when tensile propertics at low to moderate temperature are to be optimized. The three-step aging typically consists of 3 hours at $1550^{\circ} \mathrm{F}\left(843^{\circ} \mathrm{C}\right)$ followed by an air cool to low temperatures. This is then followed by eight hours at $1325^{\circ} \mathrm{F}\left(718^{\circ} \mathrm{C}\right)$, furnace cooling to $1150^{\circ} \mathrm{F}\left(621^{\circ} \mathrm{C}\right)$, eight hours at $1150^{\circ} \mathrm{F}\left(621^{\circ} \mathrm{C}\right)$, and air cooling. In the two-step aging cycle, the classic aging temperature sequence has been $1350^{\circ} \mathrm{F}\left(732^{\circ} \mathrm{C}\right)$ followed by $1150^{\circ} \mathrm{F}\left(621^{\circ} \mathrm{C}\right)$. Improvement in the Charpy energy can be obtained by optimizing the aging temperatures for specific levels of alloy hardener. The precipitation reaction of gamma prime and gamma double prime is sluggish in Alloy 706 compared to Alloy 718 . Aging times are typically eight hours at each temperature, but there is little change in properties if times are extended to 16 hours. A slight increase in strength can be achieved if a third aging treatment at $1050^{\circ} \mathrm{F}\left(566^{\circ} \mathrm{C}\right)$ is added to the $1350 / 1150^{\circ} \mathrm{F}$ sequence.

\section{Typical Property Levels and Microstructure of Large Forged Disks}

Extensive testing has been performed at GE Power Generation to verify the level and uniformity of critical turbine design properties. Tensile and Charpy properties are measured in the tangential and axial directions at both the rim and the bore (centerline) of each Alloy 706 forging used in " $F$ " class gas turbines. Average properties for triple melted wheel and spacer forgings are shown in Figure 10. The property levels are generally uniform from the center to the rim. Axial ductilities and Charpy energies tend to be slightly lower than the tangential values, but are still relatively high. Figure 11 shows typical hot tensile properties for the rim and the bore in the tangential direction up to $1000^{\circ} \mathrm{F}$. Strength levels remain generally high over the entire temperature range and no reduction of ductility is observed. Figure 12 shows a representative microstructure for solution treated and aged Alloy 706. The grains are predominantly equiaxed with some twins. The gamma prime and gamma double prime hardening phases can be observed only by TEM.

Several hundred low cycle fatigue tests have been run on samples taken from large wheel and spacer forgings. Figure 13 shows the average low cycle fatigue life with $A=1,20$ CPM at room temperature. Results at temperatures up to $900^{\circ} \mathrm{F}\left(482^{\circ} \mathrm{C}\right)$ show a slight increase of fatigue life as temperature increases. The fatigue crack growth rate was found to exhibit a small increase over the temperature range from $70^{\circ} \mathrm{F}\left(21^{\circ} \mathrm{C}\right)$ to $900^{\circ} \mathrm{F}\left(482^{\circ} \mathrm{C}\right)$. Figure 14 shows the average fatigue crack growth rate at room temperature. Fracture toughness, which characterizes a material's tolerance for defects, is high, averaging about $180 \mathrm{ksi} \sqrt{\mathrm{in}}$. despite the large size of the forgings. 

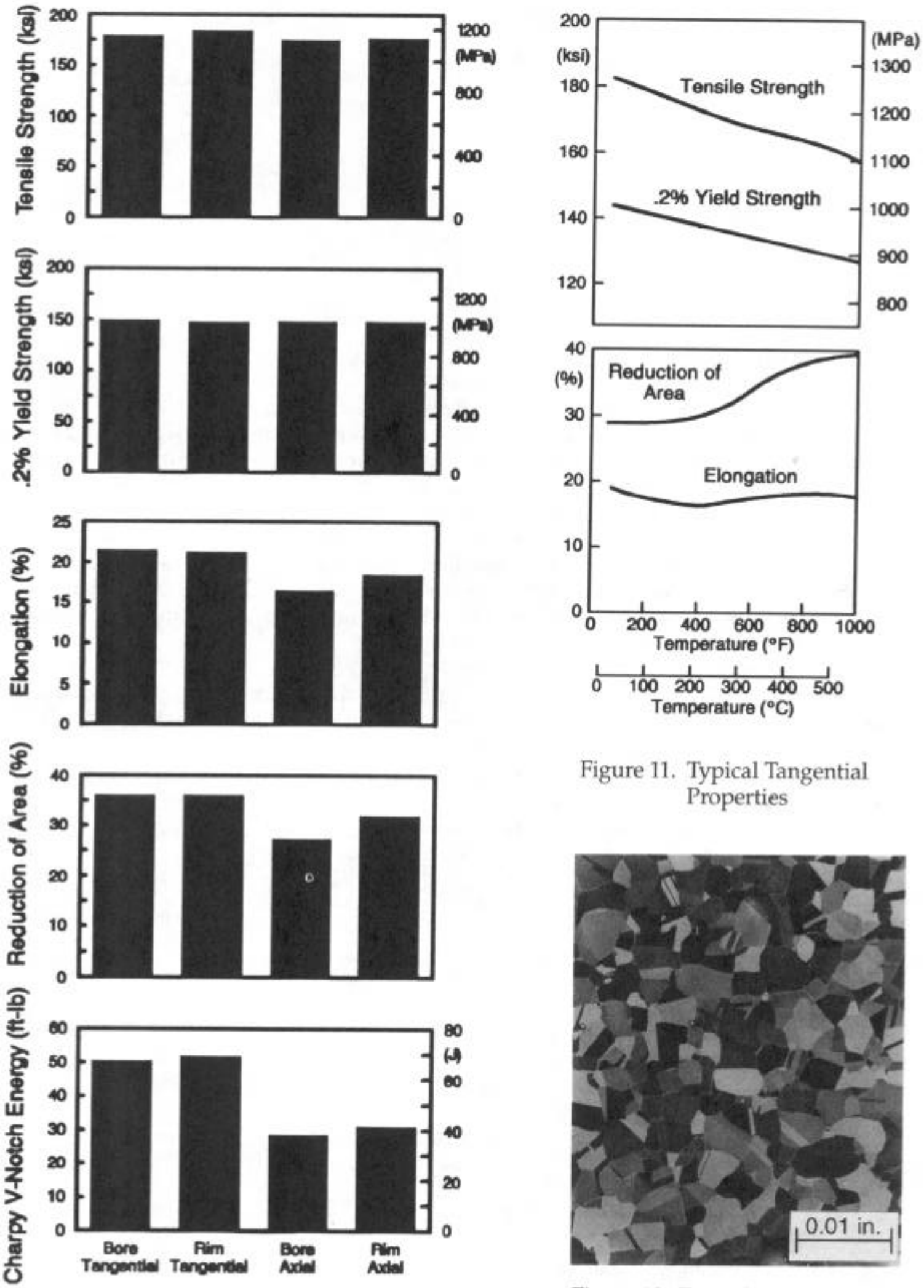

Figure 11. Typical Tangential Properties

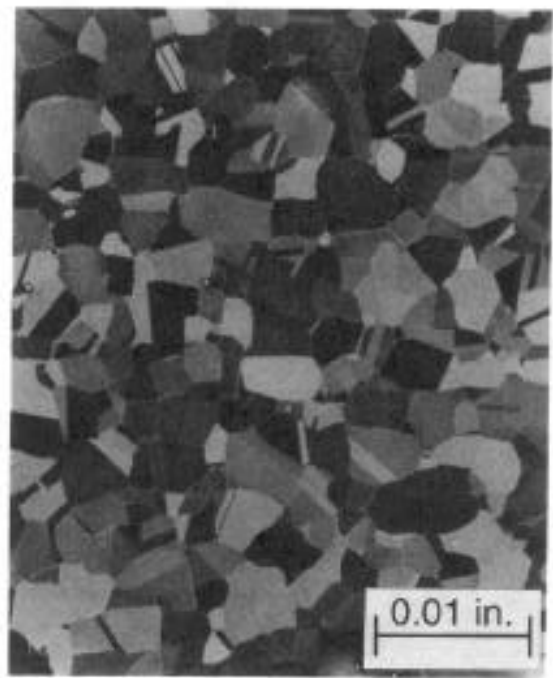

Figure 12. Typical Alloy 706 Microstructure 


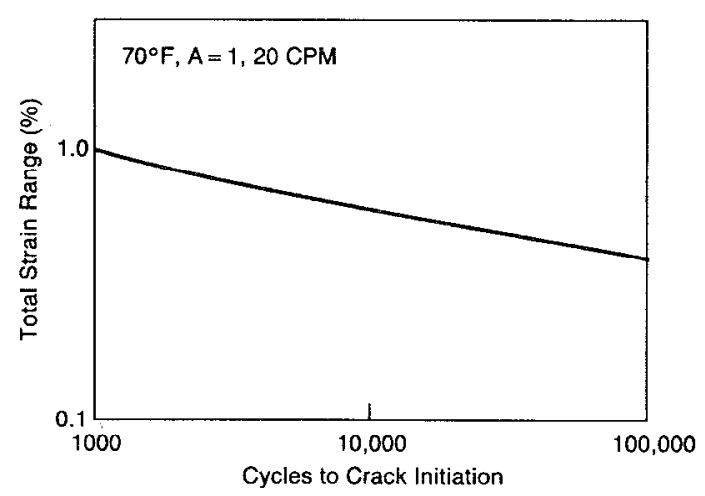

Figure 13. Low Cycle Fatigue

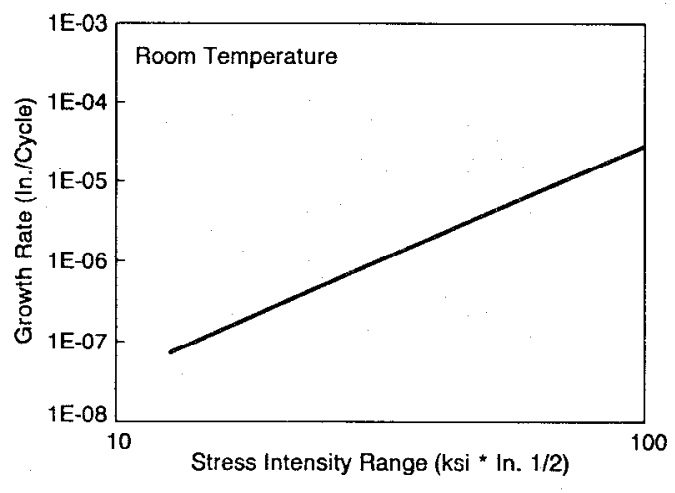

Figure 14. Fatigue Crack Growth Rate

\section{Non-Destructive Testing}

Special ultrasonic examination methods and equipment were developed to optimize the inspection of large Alloy 706 turbine wheels and spacers ${ }^{(15)}$. The Alloy 706 forgings are examined by ultrasonic inspertion from every available surface. The top and bottom surfaces of the disk-shaped forgings are examined using a $21 / 4 \mathrm{MHz}$ long wave beam. The bore surface of all wheels is examined using a specially designed portable quasiimmersion test. During this inspection, a longitudinal beam searches for axialcircumferential indications while an angle beam, moving first in a clockwise direction and then in a counterclockwise direction, is used to look for axial-radial indications. The dovetail region of each wheel is interrogated with a $60^{\circ}$ angle beam in both clockwise and counterclockwise directions.

To guarantee the highest structural integrity of these components, a special ultrasonic test was developed to inspect each forging in the plane perpendicular to the highest operating stress, (i.e., the axial-radial plane). This test, called the "Pitch-Catch" test, is performed on Alloy 706 turbine rotor components near the highly stressed bore region. The Pitch-Catch test uses two search units operated in the transmit-receive mode. A schematic diagram of the test setup is shown in Figure 15. The search units are directed toward an axial-radial plane of the forging. As the forging rotates, its axial-radial planes pass through the beam path intersection, creating the inspection volume. After one rotation, a toroid of material has been inspected. The search units are then swept radially in unison to complete the inspection of one

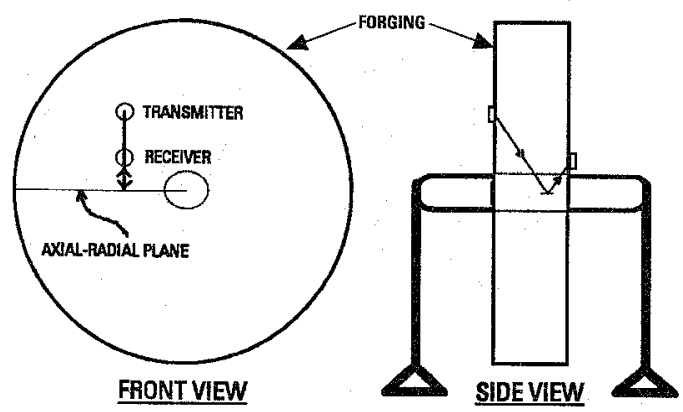

Figure 15. Pitch-Catch Test Setup axial slice, or plane of material. To complete the process, the search units are moved relative to each other so that the beam path intersection moves axially across the forging.

\section{Conclusion}

Alloy 706 is now being successfully used in large land-based heavy-duty gas turbine components. Its excellent chemistry balance has allowed very large ingots to be produced and forged into high-quality turbine wheel and spacer forgings. Hundreds of these forgings have been applied to the ncw GE series of " $\mathrm{F}$ " class gas turbines produced over the past five years; some wheels have accumulated more than 25,000 hours of successful operation. 


\section{References}

1. H.L. Eiselstein and D.J. Tillack, "The Invention and Definition of Alloy 625," Superalloy 718,625 and Various Derivatives, Minerals, Metals \& Materials Society, Warrendale, PA, ed. Edward A. Loria, 1991.

2. H.L. Eiselstein, Properties of Inconel Alloy 706, Materials Engineering Congress, Cleveland, 1970.

3. L. Rémy, J. Laniesse, and H. Aubert, Precipitation Behavior and Creep Rupture of 706 Type Alloys, Materials Science and Engineering, 38 (1979), 227-239.

4. H.L. Eiselstein, "Properties of a Fabricable, High Strength Superalloy," Metals Engineering Quarterly (Nov. 1971), 20-25.

5. K.A. Heck, "The Time-Temperature-Transformation Behavior of Alloy 706," International Special Emphasis Symposium on Superalloys 718, 625, 706 and Derivatives, Sponsored by TMS, Pittsburgh, PA (June 1994).

6. D.R. Muzyka and G.N. Maniar, "Microstructure Approach to Property Optimization in Wrought Superalloys," Metallography - A Practical Tool for Correlating the Structure and Properties of Materials, ASTM STP 557, American Society for Testing and Materials (1974), 198-219.

7. J.H. Moll, G.N. Maniar, and D.R. Muzyka, "The Microstructure of 706, a New Fe-Ni Base Superalloy," Metallurgical Transactions, 2, (8) (August 1971), 2143-2151.

8. A.M. Johnson and K.E. Fritz, "Properties and Microstructure of a Large Forged Superalloy Turbine Wheel," Superalloys - Metallurgy and Manufacture, AIME (1976), 25-35.

9. F.S. Suarez, J.E. Roberts, and L.D. Schley, "Ingot Optimization in a Superalloy - Inconcl Alloy 706," Fifth International Symposium on Electroslag and Other Special Melting Technologies, Carnegie-Mellon Institute of Research, Pittsburgh, PA (1975), 126-149.

10. Inconel Alloy 706, Technical Brochure, International Nickel Company, Inc. (1974), 13.

11. L.A. Jackman, G.E. Maurer, and S. Widge, "New Knowledge About White Spots in Superalloys," Advanced Materials \& Processes (May 1993), 18-25.

12. S.V. Thamboo, "Melt Related Defects in Alloy 706 and Their Effects on Mechanical Properties," International Special Emphasis Symposium on Superalloys 718, 625, 706 and Derivatives, Sponsored by TMS, Pittsburgh, PA (June 1994).

13. C.P. Sullivan and M.J. Donachie, "Microstructures and Mechanical Properties of IronBase (Containing) Superalloys," Metals Engineering Quarterly (Nov. 1971), 1-11.

14. D.R. Muzyka, "Controlling Microstructures and Properties of Superalloys Via Use of Precipitated Phases," Metals Engineering Quarterly (Nov. 1971), 12-19.

15. R.V. Falsetti, "Ultrasonic Inspection of Large Inconel 706 Forgings," ASNT Fall Conference Program Summary (1993), 139-141. 


\section{Acknowledgments}

The Authors would like to acknowledge the advice and effort provided by Ed Raymond of GE Aircraft Engines, and Sam Thamboo and D. K. Sharma of GE Power Generation in developing the information presented in this paper. 